\title{
From the Desk of the Editor
}

\author{
K. Harish ${ }^{1,2}$
}

Received: 27 July 2016 / Accepted: 28 July 2016 /Published online: 29 August 2016

(C) Indian Association of Surgical Oncology 2016

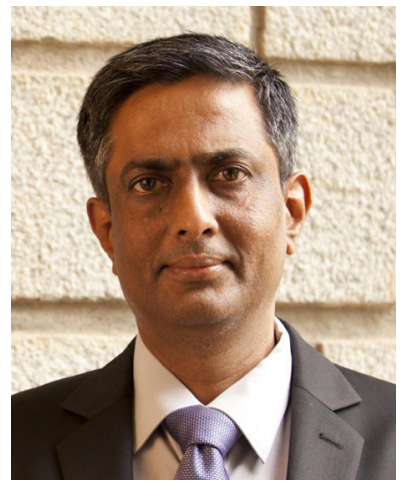

The understanding of cancers has opened new vistas in the management of cancers. Cancers hitherto considered as advanced and suitable for palliation or supportive care are now being addressed more aggressively with curative intent. One such area is the peritoneal malignancy. Peritoneum is now considered an 'organ' by itself. Peritoneal carcinomatosis in ovarian cancer alone was considered appropriate for surgical resection while in gastrointestinal and other cancers, it was considered 'metastatic' disease and suitable for palliation. Over the last two decades, this 'myth' has been dispelled and multimodal therapy including cytoreductive surgery, followed by hyperthermic intraperitoneal chemotherapy

K. Harish

drkhari@yahoo.com

1 Department of Surgical Oncology, HCG MSR Cancer Centre, M S Ramaiah Medical College, Bangalore 560054, India

2 2866, 13TH Main 'E’ Block, Subramanyanagar, Bangalore 560010, India
(HIPEC), has been developed into standard of care [1, 2]. A special emphasis needs to be placed on the team. It shall include at least the surgical oncologist, medical oncologist, anaesthesiologist, intensivist, and the psycho oncologist. This issue contains pre-operative assessment for peritoneal cytoreduction by the pioneer himself. As more institutes start practicing HIPEC in India, apart from competence, the concerns of complications and cost need to be addressed.

The vast pool of patients in India makes us wonder as to why we are not the 'trend setters' in the management of most areas of cancer. Both patient and physician issues need to be addressed. The cancer registries including both the population based and hospital based ones are covering more areas of the country. Many government-run health schemes are now catering to oncology. This would ensure access to total cancer care for large sections of society which were deprived of such a facility for long. Such schemes also emphasize and mandate the need for tumor board decisions involving all oncologists. The treatment modalities thus are getting more standardized. Hence, India has a huge potential to assess the disease outcomes. An insight into the same and a stimulus for us to do so beckons us.

\section{References}

1. Sugarbaker PH (2016) Cytoreductive surgery and hyperthermic intraperitoneal chemotherapy in the management of gastrointestinal cancers with peritoneal metastases: progress toward a new standard of care. Cancer Treat Rev 48:42-49. doi:10.1016/j.ctrv.2016.06.007

2. Brucher BL, Piso P, Verwaal V, Esquivel J, Derraco M, Yonemura Y, Gonzalez-Moreno S, Pelz J, Konigsrainer A, Strohlein M, Levine EA, Morris D, Bartlett D, Glehen O, Garofalo A, Nissan A (2012) Peritoneal carcinomatosis: cytoreductive surgery and HIPEC - overview and basics. Cancer Investig 30(3):209-224. doi:10. 3109/07357907.2012.654871 